\title{
Blends of ground tire rubber devulcanized by microwaves/ HDPE - Part A: influence of devulcanization process
}

\author{
Fabiula Danielli Bastos de Sousa ${ }^{1 *}$, Júlia Rocha Gouveia ${ }^{1}$, Pedro Mario Franco de Camargo Filho", \\ Suel Eric Vidotti', Carlos Henrique Scuracchio', Leice Gonçalves Amurin ${ }^{2}$ and Ticiane Sanches Valera ${ }^{2}$ \\ ${ }^{1}$ Centro de Engenharia, Modelagem e Ciências Sociais Aplicadas - CECS, \\ Universidade Federal do ABC - UFABC, Santo André, SP, Brazil \\ ${ }^{2}$ Departamento de Engenharia Metalúrgica e de Materiais, Escola Politécnica, \\ Universidade de São Paulo - USP, São Paulo, SP, Brazil \\ *fabiuladesousa@gmail.com
}

\begin{abstract}
The main objective of this work is the study of the influence of microwaves devulcanization of the elastomeric phase on dynamically revulcanized blends based on Ground Tire Rubber (GTR)/High Density Polyethylene (HDPE). The devulcanization of the GTR was performed in a system comprised of a conventional microwave oven adapted with a motorized stirring at a constant microwaves power and at various exposure times. The influence of the devulcanization process on the final properties of the blends was evaluated in terms of mechanical, viscoelastic, thermal and rheological properties. The morphology was also studied.
\end{abstract}

Keywords: elastomers, recycling, GTR, devulcanization, HDPE.

\section{Introduction}

The search for new materials has been a constant in the human history. Similarly, solutions to the problem of disposal of waste polymers, especially waste rubber, that causes serious environmental problems and concern, have been desired for many years. Rubber requires a long period of time to degrade naturally due to its structure of cross-linkings and the presence of stabilizers and other $\operatorname{additives}^{[1,2]}$.

The technique of devulcanization by microwaves is currently one of the most promising ones, based on the good properties of the devulcanized material and the possibility of high productivity. The process takes advantage of volumetric heating of the material by microwaves, promoting a more uniform heating than that achieved by traditional methods of heating, which depend on conduction and/or convection ${ }^{[3-5]}$. Materials react differently when exposed to an electromagnetic field, like the one generated by microwaves. In dielectric materials, molecules or free ions are rearranged in dipole momentum which results in the volumetric heating through the volume of the material. These molecules vibrate at high frequency tending to re-orient and align themselves with the microwave field. Interaction between the material and the microwave energy generates heat. The ability to convert microwave energy into thermal energy depends on the magnitude of the dielectric loss of the material ${ }^{[6,7]}$. Therefore, in mixtures of materials, it is possible a selective heating of specific regions, a property that has been exploited in the processing of thermosets with mineral fillers ${ }^{[3-5]}$. Elastomers such as natural rubber (NR), styrene-butadiene rubber (SBR), and ethylene propylene diene monomer rubber (EPDM) have low microwaves absorption due to their non polar characteristic. This limitation can be overcome by the addition of conductive filler like carbon black ${ }^{[8-10]}$.
According to Scuracchio et al. ${ }^{[3]}$, the technique of devulcanization by microwaves is able to generate a material with properties quite different from the original vulcanized rubber. Among the properties, the most remarkable is the ability to flow and to be remolded. This feature, allied to the possibility of its revulcanization, indicates the wide applicability of the technique. Bani et al. ${ }^{[1]}$ demonstrated that microwaves can be applied easily and have many advantages, such as high heating rate, without any need of additional mechanical or chemical treatments.

On the other hand, thermoplastic vulcanized (TPVs) are a kind of polymeric blend produced via dynamic vulcanization of a dispersed elastomeric phase, i.e. the selective cross-linking of the rubber phase while mixed with the molten thermoplastic ${ }^{[12]}$. The final morphology consists of cross-linked rubber particles dispersed in a thermoplastic matrix. The thermoplastic matrix is responsible for the processability of TPVs, while the cross-linked elastomer particles are responsible for the elasticity at room temperature. The final morphology of this kind of material is the main responsible for the rheological and physical properties beyond being controlled by the processing conditions and characteristics of the constituting materials ${ }^{[13]}$.

The balance between break-up and coalescence of the droplets of the elastomeric phase provides the final morphology of a TPV during processing. In the special case of TPV composed by devulcanized elastomer as dispersed phase, the devulcanization acts increasing the break-up ability while the revulcanization acts decreasing the coalescence, and both effects contribute to the refinement of the morphology. In addition, higher amounts of recycled rubber can be added in the blend without properties degradation, since 
the devulcanization process tends to increase the adhesion of the particles on the thermoplastic phase.

In this work, the influence of microwaves devulcanization of the elastomeric phase in the blends GTR/HDPE is investigated. The results show that microwaves treatment of the GTR in the blends can influence the mechanical, viscoelastic, thermal and rheological properties.

\section{Experimental}

\subsection{Materials}

HDPE IA-59, a grade for injection molding, was kindly supplied by Braskem (MFI = 7.3 g/10min). Ground waste truck tire (GTR) separated from non elastomeric components; rubber accelerator N-tert-butyl-2-benzothiazole sulfenamide (TBBS) and sulfur were kindly supplied by Pirelli Pneus Ltda.

\subsection{Devulcanization of GTR and mixture with vulcanization additives}

GTR was devulcanized in a system comprised of a conventional microwave oven adapted with a motorized stirring system with speed control. The devulcanization process was done by using the maximum power of the oven, i.e. $820 \mathrm{~W}$. The time at which the material was exposed to microwaves ranged from 1 to 5 minutes and also 2-2, 2-2-2, and 3-3, where the numbers represent the exposure time to microwaves (minutes) and the hyphen corresponds to an interval of 10 minutes between consecutive treatments, under stirring with the oven switched off.

The devulcanized GTR was mixed with the vulcanization additives by using a laboratory two roll mill PRENMAR for approximately 6 minutes at room temperature. To promote the dynamic revulcanization during the processing with the thermoplastic, $1 \mathrm{phr}$ of accelerator TBBS and $1 \mathrm{phr}$ of sulfur were added.

\subsection{Preparation of the blends}

The blends were prepared in an internal mixer coupled to a torque Rheometer Polylab 900 at $160^{\circ} \mathrm{C}$ and $80 \mathrm{rpm}$ for 15 minutes. The compositions and nomenclature used for the blends are summarized in the Table 1.

\subsection{Characterization}

The revulcanization characteristics of the devulcanized GTRs under different exposure times to microwaves were studied by using an oscillatory dual cone Monsanto Rheometer 100, according to ASTM D1646-07. Curves of torque versus time were obtained at $160^{\circ} \mathrm{C}$. The nomenclature is type GTRX $+\mathrm{ad}$, where $\mathrm{X}$ represents the exposure time of GTR to microwaves and " $+\mathrm{ad}$ " the presence of vulcanization additives.

Thermal properties of the HDPE phase were analyzed by Differential Scanning Calorimetry (DSC) in a DP Union DSC Q200 under nitrogen atmosphere. The samples were heated from room temperature to $190^{\circ} \mathrm{C}$ and were held at this temperature for $3 \mathrm{~min}$ to eliminate their thermal history and destroy the HDPE crystalline nuclei. They were then cooled to $-90^{\circ} \mathrm{C}$ and were subsequently heated to $200^{\circ} \mathrm{C}$. All the steps were performed at a rate of $10^{\circ} \mathrm{C} / \mathrm{min}$.

Mechanical properties of the blends were analyzed by tensile tests in an Instron Universal Testing Machine 3369 with a $10 \mathrm{kN}$ load cell at a crosshead speed of $50 \mathrm{~mm} / \mathrm{min}$. The samples were prepared in the shape of plates by compression molding at $160^{\circ} \mathrm{C}$ in a hydraulic press, and then the blends were cut into dumb-bell shaped tensile test according to ASTM D412, type IV

Rheological properties of the blends were analyzed by small amplitude oscillatory rheometry in frequency sweep mode, by using a parallel plate rheometer Anton Paar CTD450 (diameter $25 \mathrm{~mm}$, gap $1.3 \mathrm{~mm}, 0.5 \%$ strain for the viscoelastic linear response at $170^{\circ} \mathrm{C}$ under inert atmosphere)

Dynamic mechanical properties of the blends were analyzed by using a Dynamic Mechanical Analyzer (DMA) Q800 TA Instruments. The analyses were performed by Single Cantilever mode, frequency of $1 \mathrm{~Hz}$, temperature ranging from -100 to $140^{\circ} \mathrm{C}$ and heating rate of $3^{\circ} \mathrm{C} / \mathrm{min}$.

A Jeol JMS-6701F Scanning Electron Microscope was used to observe the morphology of the blends with working distance of $5.5 \mathrm{~mm}$. The samples were firstly pressed by using a hydraulic press, cut, fractured just after being immersed in liquid nitrogen and then coated with golden by using a sputter coater.

Table 1. Nomenclatures and compositions of the blends produced in this work.

\begin{tabular}{|c|c|c|c|c|}
\hline Nomenclature & GTR amount (wt\%) & HDPE amount (wt\%) & $\begin{array}{c}\text { Devulcanization time of } \\
\text { GTR (min) }\end{array}$ & $\begin{array}{c}\text { Presence of } \\
\text { vulcanization additives }\end{array}$ \\
\hline 80GTR0/20HDPE & 80 & 20 & - & - \\
\hline 80GTR0+ad/20HDPE & 80 & 20 & - & Yes \\
\hline 80GTR1+ad/20HDPE & 80 & 20 & 1 & Yes \\
\hline 80GTR2+ad/20HDPE & 80 & 20 & 2 & Yes \\
\hline 80GTR3+ad/20HDPE & 80 & 20 & 3 & Yes \\
\hline 80GTR4+ad/20HDPE & 80 & 20 & 4 & Yes \\
\hline 80GTR5+ad/20HDPE & 80 & 20 & 5 & Yes \\
\hline 80GTR2-2+ad/20HDPE & 80 & 20 & $2-2$ & Yes \\
\hline 80GTR2-2-2+ad/20HDPE & 80 & 20 & $2-2-2$ & Yes \\
\hline 80GTR3-3+ad/20HDPE & 80 & 20 & $3-3$ & Yes \\
\hline
\end{tabular}




\section{Results and Discussion}

\subsection{Revulcanization characteristics}

Torque versus time curves of devulcanized rubber containing vulcanization additives are showed in the Figure 1.

According to Figure 1, the samples GTR5, GTR2-2-2 and GTR3-3 presented reversion trend, i.e. the torque measured by the equipment tends to decline at the end of the analysis. This behavior happened probably as consequence of degradation of rubber main chains, since these samples were exposed to microwaves for long periods of time.

The revulcanization characteristics of the samples, calculated from the curves presented in the Figure 1 are summarized in the Table 2. In general, it can be observed that the optimum cure time and scorch time, represented by $t_{90}$ and ts ${ }_{1}$ respectively, were lower for samples with the highest exposure times to microwaves in one step as well as in multistep treatments. This behavior is characteristic of reclaimed rubber and it was observed by some other authors ${ }^{[14-17]}$, which probably happens due to the presence of residual curatives from the first vulcanization. The devulcanization process increases the freedom degree of the polymeric chains, accelerating the reaction with the increasing of the exposure time of the GTR to microwaves, possibly due to the great amount of effective shocks during the process.

GTR5+ad, GTR2-2+ad and GTR3-3+ad presented lower values of $\mathrm{ML}$ and $\mathrm{MH}$, minimum and maximum torque respectively, which demonstrates lower cross-linking densities in comparison to the other samples. The values of the subtraction of MH-ML did not present a trend, but they were lower in relation to GTR0+ad, with exception of the samples GTR1+ad and GTR3+ad. This value is related to the cross-linking density of the sample and its reduction is attributed to the breaking of reticulation as a result of the devulcanization by microwaves.

It can be also observed that the samples with higher values of CRA (Cure Rate Average) were exposed to microwaves for 2 minutes, in two or three steps of treatment. CRA values were calculated according to Equation $1^{[18]}$ :

$$
C R A=\frac{1}{t_{90}-t s_{1}}
$$

where $t_{90}$ is the optimum cure time and $t_{s 1}$ the scorch time. The value is proportional to the average slope of torque versus time curve or, in other words, it is proportional to the rubber revulcanization speed.

The devulcanization process reduced the ML values with the increase of the exposure time to microwaves. However, a clear trend was not observed. As the ML value is proportional to the initial viscosity of the sample ${ }^{[19]}$, the increase of the exposure time to microwaves reduced the viscosity of rubber induced by the breaking of the three-dimensional network of the vulcanized GTR. The sample GTR3 presented the highest ML value probably due to the formation of new bonds in the rubber, since during sample exposure to
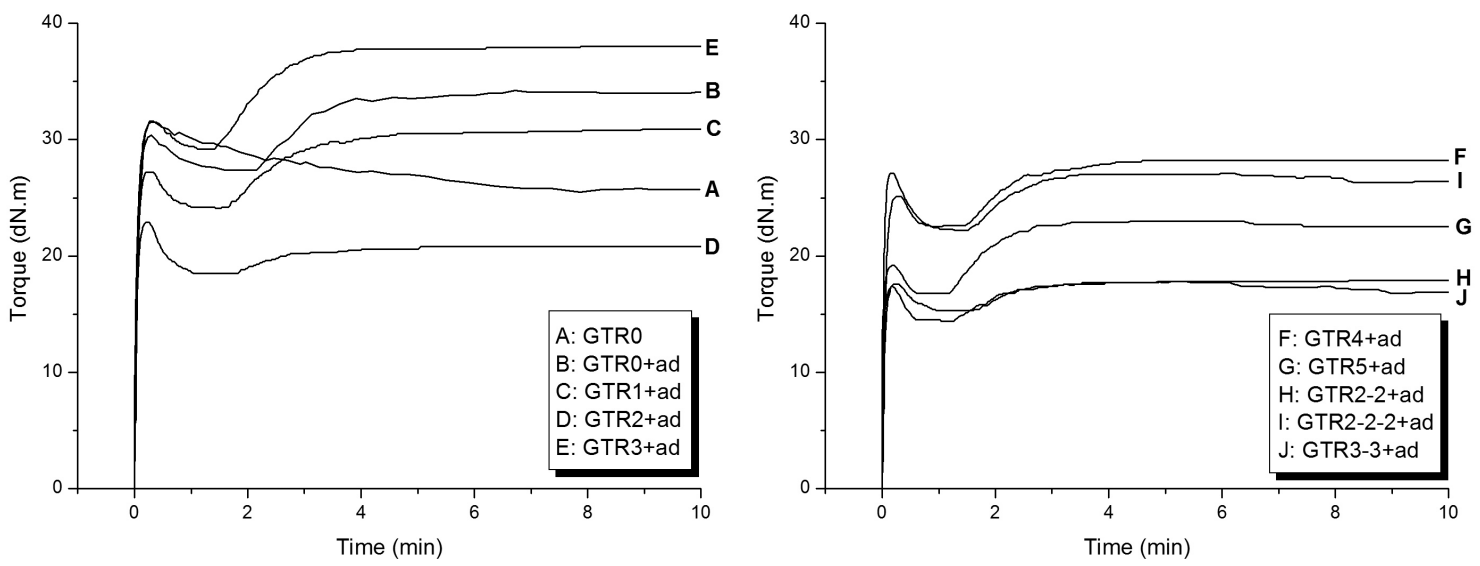

Figure 1. Torque versus time curves of devulcanized rubber containing vulcanization additives. The curves were separated for better visualization and analysis of results, and GTR0 without vulcanization additives was also analyzed for comparison.

Table 2. Revulcanization behavior of the GTRs devulcanized by microwaves.

\begin{tabular}{|c|c|c|c|c|c|c|}
\hline Sample & $t_{90}(\min )$ & $\mathrm{ts}_{1}(\mathrm{~min})$ & ML (dN.m) & MH (dN.m) & MH-ML (dN.m) & CRA $\left(\min ^{-1}\right)$ \\
\hline GTR0+ad & 2.90 & 2.16 & 27.40 & 34.00 & 6.60 & 1.35 \\
\hline GTR1+ad & 2.45 & 1.59 & 24.10 & 30.90 & 6.80 & 1.16 \\
\hline GTR2+ad & 1.97 & 1.89 & 18.50 & 20.80 & 2.30 & 12.50 \\
\hline GTR3+ad & 2.28 & 1.48 & 29.20 & 38.00 & 8.80 & 1.25 \\
\hline GTR4+ad & 2.04 & 1.52 & 22.50 & 28.20 & 5.70 & 1.92 \\
\hline GTR5+ad & 1.95 & 1.25 & 16.80 & 23.00 & 6.20 & 1.43 \\
\hline GTR2-2+ad & 1.88 & 1.61 & 15.30 & 17.90 & 2.60 & 3.70 \\
\hline GTR2-2-2+ad & 2.06 & 1.59 & 22.20 & 27.00 & 4.80 & 2.13 \\
\hline GTR3-3+ad & 1.85 & 1.34 & 14.40 & 17.70 & 3.30 & 1.96 \\
\hline
\end{tabular}


microwaves, bonds can be broken and created at the same time $^{[20]}$. Therefore, depending on the time at which the sample was exposed to microwaves, the former event can exceed the later one or vice-versa. On the other hand, the sample GTR3-3 presented the lowest ML value obtained, which may be due to degradation of the rubber by the high exposure time of the sample to microwaves.

\subsection{Processing behavior of the blends}

According to Shahbikian et al. ${ }^{[21]}$, the advantage of using internal mixer to produce TPV is the possibility of monitoring the effect of each component on the torque/temperature evolution of the blend. Some researchers use this advantage to examine different phenomena such as dynamic vulcanization ${ }^{[21-29]}$, as performed in this work.

During the mixing, just after the addition of the matrix phase and as soon as the torque measured by the equipment was stabilized, GTR (containing or not vulcanization additives) was added into the mixer, what permitted the analysis of the dynamic revulcanization behavior of the blends, which is shown in Table 3. The $\mathrm{M}_{\text {Final }}$ values represent the torque measured by the equipment at the end of the mixing process.

In general, $t_{90}$ and $t_{1}$ values of the blends were much smaller than the values of the neat rubber obtained by using a rheometer (Table 2), which shows that the dynamic revulcanization reaction occurred with higher rate. Consequently, the CRA values of the blends were also higher in comparison to the neat rubber, which confirms, as just verified through the results of $t_{90}$ and $t_{1}$, that the dynamic revulcanization reaction occurred more quickly in comparison to revulcanization (exception: GTR2+ad, in which the highest reaction rate happened). It happened possibly due to higher shear rates generated within the internal mixer during processing.

However, the values of ML, MH and the subtraction of MH-ML were not analyzed in this section and compared with the ones of the neat rubber (section 3.1), since they also take into consideration the viscosity of the HDPE phase (among other factors) and it may lead to erroneous conclusions.

In general, but with some exceptions, it was verified a trend towards the reduction in the $\mathrm{M}_{\text {Final }}$ values of blends (concerning the final viscosity of blends) as the exposure time of GTR to microwaves got higher, what demonstrates that the GTR devulcanization increased the fluidity of this phase. The cross-linking density and a possible degradation of the thermoplastic phase may also have influenced the
$\mathrm{M}_{\text {Final }}$. The fluidity of rubber facilitates the processing, its dispersion into other polymers to form a polymer blend, as well as the revulcanization reaction.

\subsection{Oscillatory rheometry}

The storage modulus (G') and complex viscosity ( $\left.\eta^{*}\right)$ of the blends $80 \mathrm{GTR} / 20 \mathrm{HDPE}$, as function of the frequency, are summarized in the Figure 2.

In order to facilitate the analysis of the results, a table of the $\mathrm{G}^{\prime}$ at the minimum and maximum frequencies of all the blends was created (Table 4).

According to the Figure 2, the complex viscosity decreased with the increase of the frequency, which clearly shows the pseudoplastic behavior of the blends, assuming the Cox Merz rule ${ }^{[30-35]} . \eta^{*}$ of the dynamically revulcanized blends are higher than the blend 80GTR0/20HDPE due the increase of the cross-linking density of the GTR phase ${ }^{[35]}$.

Being G' proportional to the stored energy ${ }^{[36]}$, this value is proportional to the elasticity or, in other words, to the cross-linking density of the elastomeric phase of the blend. $\mathrm{G}^{\prime}$ is influenced also by morphology of the blends ${ }^{[28,37]}$. The morphology refinement and compatibility tend to increase the G'values. According to SEM micrographs, no conclusion about the morphology refinement of the blends can be made, but the mechanical properties results alert to the poor adhesion between the phases. The blends that presented the lowest elongation at break results were the same that presented the lowest $G$ ' at minimum frequency (80GTR4+ad/20HDPE, 80GTR5+ad/20HDPE and 80GTR3-3 $+\mathrm{ad} / 20 \mathrm{HDPE})$, which can have been result of the poor adhesion, occurring a possible particle detachment from the matrix when applied an external stress.

\subsection{Dynamic mechanical properties}

The temperature dependence of $\tan \delta$ of the blends is shown in the Figure 3.

According to the Figure 3, there are two transitions related to the phases of the blends: the first one around $-30^{\circ} \mathrm{C}$ refers to the glass transition ( $\mathrm{T}_{\mathrm{a}}$ ) of the GTR and the other refers to $\alpha$ transition of the HDPE phase $\left(\mathrm{T}_{\alpha}\right)$ around $100^{\circ} \mathrm{C}$. The existence of two distinct transitions confirms the immiscible character of the blends. It can also be observed that there is a trend towards the reduction of the area under the peak related to GTR transition, as well as the reduction

Table 3. Dynamic revulcanization behavior of the of the blends $80 \mathrm{GTR} / 20 \mathrm{HDPE}$

\begin{tabular}{|c|c|c|c|c|}
\hline Blend & $t_{90}(\min )$ & $\mathrm{ts}_{1}(\mathrm{~min})$ & $\operatorname{CRA}\left(\min ^{-1}\right)$ & $M_{\text {Final }}(\mathrm{dN} . \mathrm{m})$ \\
\hline 80GTR0/20HDPE & & & & 107.00 \\
\hline 80GTR0+ad/20HDPE & 1.17 & 0.75 & 2.38 & 108.00 \\
\hline 80GTR1+ad/20HDPE & 0.95 & 0.75 & 5.00 & 106.00 \\
\hline 80GTR2+ad/20HDPE & 0.65 & 0.48 & 5.88 & 111.00 \\
\hline 80GTR3+ad/20HDPE & 1.15 & 0.95 & 5.00 & 92.50 \\
\hline 80GTR4+ad/20HDPE & 1.13 & 0.72 & 2.44 & 93.90 \\
\hline 80GTR5+ad/20HDPE & 1.01 & 0.68 & 3.03 & 63.10 \\
\hline 80GTR2-2+ad/20HDPE & 0.80 & 0.45 & 2.86 & 103.00 \\
\hline 80GTR2-2-2+ad/20HDPE & 0.75 & 0.50 & 4.00 & 96.20 \\
\hline 80GTR3-3+ad/20HDPE & 1.05 & 0.68 & 2.70 & 54.30 \\
\hline
\end{tabular}


of the height of the same peak, which is due to mobility restriction generated by cross-linkings of this phase $\mathrm{e}^{[32,38,39]}$.

$\mathrm{T}_{\mathrm{g}}$ values of the devulcanized rubber and rubber phases of the blends were obtained from the values of maximum peaks of the curves $\tan \delta$ versus temperature. These values are shown in the Figure 4.

According to the Figure 4, three zones of distinct $T_{g}$ behaviors can be determined. They were divided into continuous, dotted and dashed line zones, which are described below.

Table 4. G' at the minimum ( $0.01 \mathrm{rad} / \mathrm{s})$ and maximum $(300 \mathrm{rad} / \mathrm{s})$ frequencies of the blends.

\begin{tabular}{ccc}
\hline Blend & $\begin{array}{c}\mathbf{G}^{\prime}(\mathbf{P a}) \\
\text { at } \mathbf{0 . 0 1} \mathbf{~ r a d} / \mathbf{s}\end{array}$ & $\begin{array}{c}\mathbf{G}^{\prime}(\mathbf{P a}) \\
\text { at } \mathbf{3 0 0} \mathbf{~ r a d} / \mathbf{s}\end{array}$ \\
\hline 80GTR0/20HDPE & $1.52 \times 10^{5}$ & $5.75 \times 10^{5}$ \\
80GTR0 $+\mathrm{ad} / 20 \mathrm{HDPE}$ & $2.16 \times 10^{5}$ & $5.52 \times 10^{5}$ \\
80GTR1 $+\mathrm{ad} / 20 \mathrm{HDPE}$ & $1.82 \times 10^{5}$ & $5.19 \times 10^{5}$ \\
80GTR2 $+\mathrm{ad} / 20 \mathrm{HDPE}$ & $1.76 \times 10^{5}$ & $4.95 \times 10^{5}$ \\
80GTR3 $+\mathrm{ad} / 20 \mathrm{HDPE}$ & $2.34 \times 10^{5}$ & $6.69 \times 10^{5}$ \\
80GTR4 $+\mathrm{ad} / 20 \mathrm{HDPE}$ & $1.98 \times 10^{5}$ & $5.82 \times 10^{5}$ \\
80GTR5 $+\mathrm{ad} / 20 \mathrm{HDPE}$ & $1.75 \times 10^{5}$ & $5.84 \times 10^{5}$ \\
80GTR2-2 $+\mathrm{ad} / 20 \mathrm{HDPE}$ & $2.27 \times 10^{5}$ & $5.87 \times 10^{5}$ \\
80GTR2-2-2 $+\mathrm{ad} / 20 \mathrm{HDPE}$ & $2.34 \times 10^{5}$ & $6.69 \times 10^{5}$ \\
80GTR3-3 $+\mathrm{ad} / 20 \mathrm{HDPE}$ & $2.22 \times 10^{5}$ & $6.73 \times 10^{5}$ \\
\hline
\end{tabular}

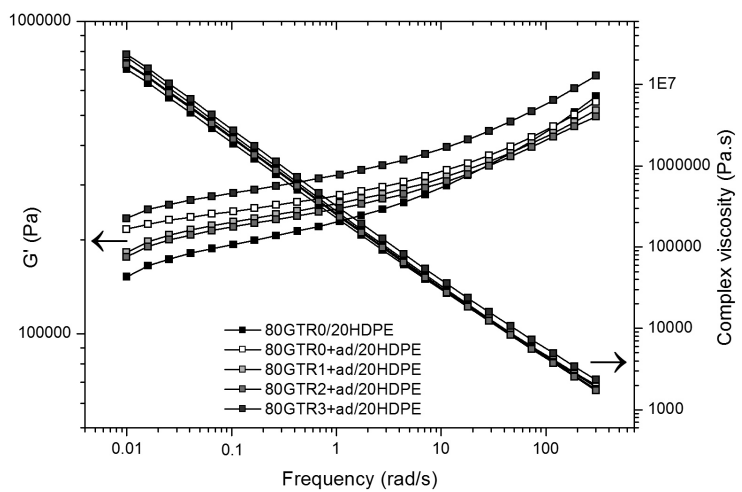

Continuous line zone: the GTR was not exposed to microwaves.

Dotted line zones: the final temperature of the GTRs after the exposure time to microwaves probably was not enough to provide high degree of devulcanization in the samples. Due to the low degree of devulcanization, there was not a significant change in $\mathrm{T}_{\mathrm{g}}$ of the rubber, which behaved just like a vulcanized one.

Dashed line zones: the final temperature of the GTRs after the exposure time to microwaves was enough to generate high degree of devulcanization in the sample. During processing of the blends, due to the devulcanization degree reached by the elastomeric phase of the samples, the rubber chains acquired some mobility, demonstrated by the increase in the $\mathrm{T}_{\mathrm{g}}$ values. In other words, the devulcanization level of the elastomeric phase influenced the dynamic revulcanization reaction, changing the $T_{g}$ value of this phase.

\subsection{Thermal properties by DSC}

The results of the DSC obtained from the second heating cycle of the blends are shown in the Table 5. The crystallization degree was calculated according to Equation $2^{[40]}$ :

$$
\chi_{c}=\left[\Delta H_{m} /\left(\Delta H_{m 100} \cdot W_{H D P E}\right)\right] \cdot 100
$$

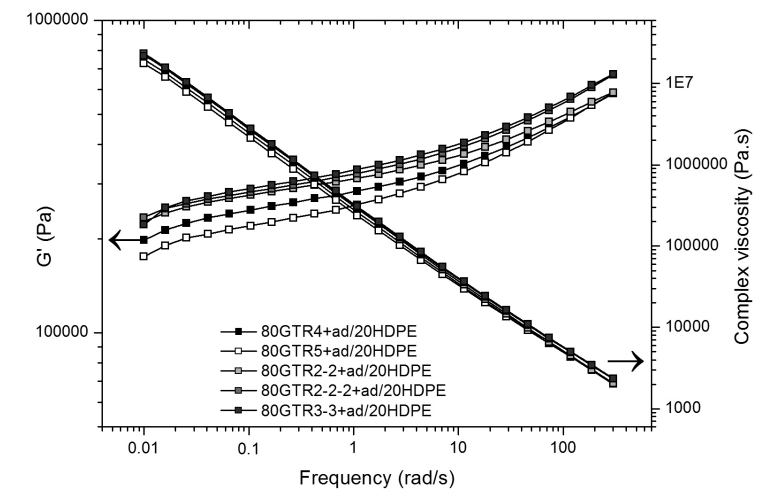

Figure 2. G' and $\eta^{*}$ versus frequency of the blends. The curves were separated for better visualization and analysis of results.
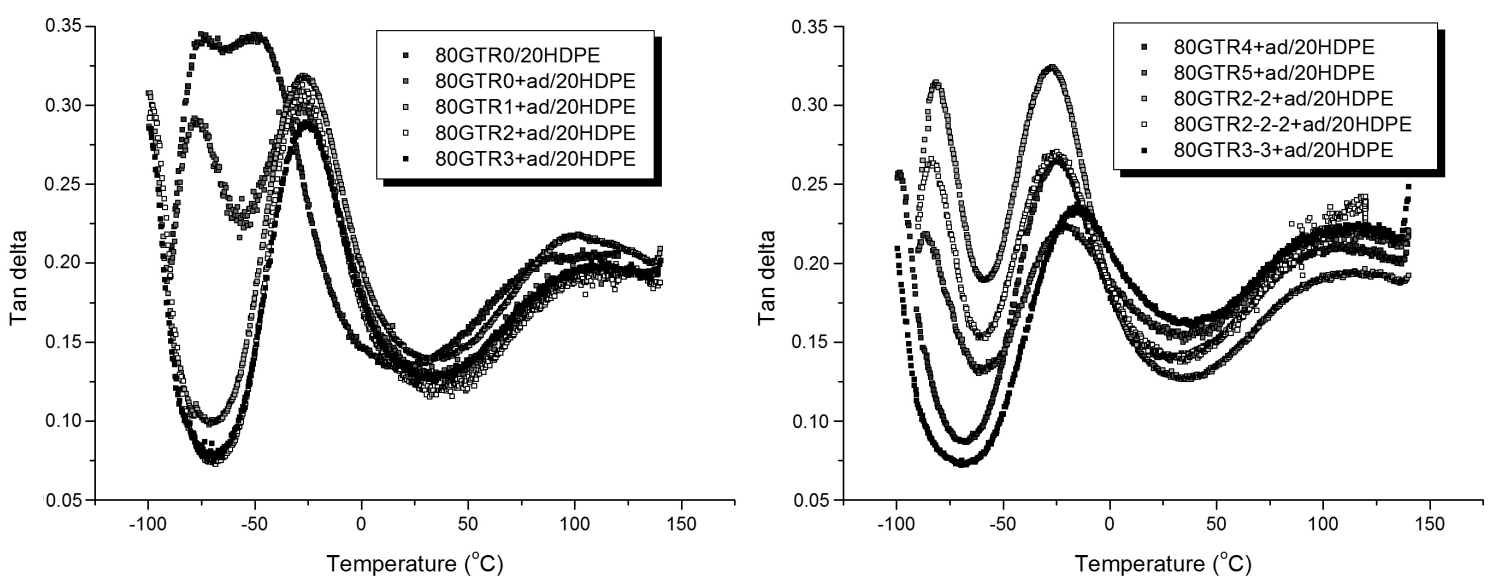

Figure 3. Tan $\delta$ versus temperature of the blends $80 \mathrm{GTR} / 20 \mathrm{HDPE}$. The curves were separated for better visualization and analysis of the results. 
where $\chi_{c}$ is the crystallization degree, $\Delta H_{m}$ is the enthalpy of melting $(\mathrm{J} / \mathrm{g}), \Delta H_{m 100}$ is the enthalpy of melting of the HDPE $100 \%$ crystalline $(293 \mathrm{~J} / \mathrm{g})^{[41]}$ and $W_{H D P E}$ is the mass fraction of HDPE in blend.

The melting temperatures of the HDPE phase did not present large variations in function of the exposure time of the GRT to microwaves. However, the crystallization degree of the HDPE phase was affected by the presence of the rubber phase.

The blends that presented the highest crystallization degree of the HDPE phase were the ones in which the GTR phase was exposed to microwaves for longer periods of time (with exception of the samples 80GTR0 $+\mathrm{ad} / 20 \mathrm{HDPE}$ and $80 \mathrm{GTR} 3+\mathrm{ad} / 20 \mathrm{HDPE}$ ). This fact is probably due to

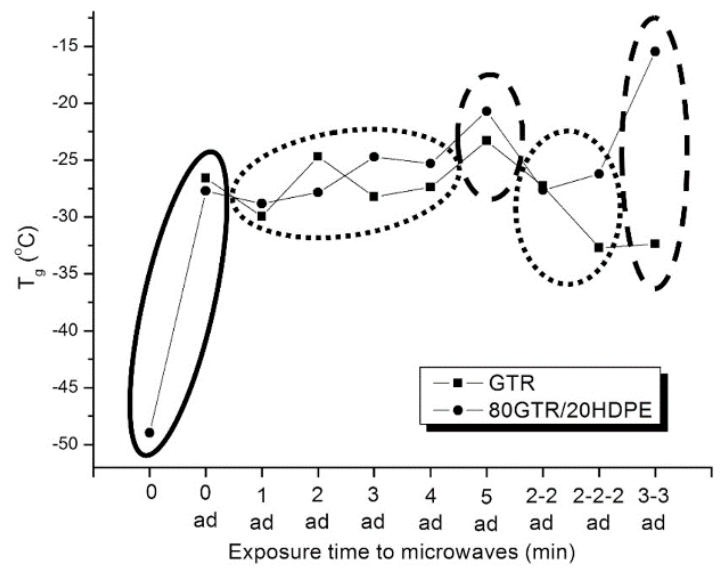

Figure 4. $T_{g}$ values of the devulcanized rubber and rubber phases of the blends as determined by DMA. the more pronounced refinement of the morphology of the blends with the increase of the exposure of the GTR to microwaves, which could not be observed by SEM micrographs. According to Utracki (p. 248) ${ }^{[42]}$, "[...] the finer the amorphous droplets are dispersed, the larger the total interfacial contact surface, and thus the higher is the possibility of nucleation at these interfaces."

\subsection{SEM}

The morphologies of some blends are shown in the Figure 5.

According to the SEM micrographs, it could be observed that the blends containing GTR with longer exposure time to microwaves presented a less coarse surface in comparison to the other blends as a result of a lower fracture resistance to the external force applied on the blends. This tendency was also observed in the results of mechanical properties (see section 3.7). Regarding the morphology refinement, no conclusions can be made because the impossibility to distinguish the phases from the presented SEM micrographs. In the blend 80GTR3-3/20HDPE some voids can clearly be observed (arrows in the Figure $5 \mathrm{f}$ ) probably due to the degradation of the rubber phase and poor degree of interfacial adhesion between the phases of the blend.

\subsection{Mechanical properties}

The main results of the tensile tests of the blends are presented in the Table 6 .

On the whole but with some exceptions, the values of stress at break and elongation at break reduced as the exposure time of GTR to microwaves got higher, while the values of Young's modulus presented an opposite behavior. The tensile
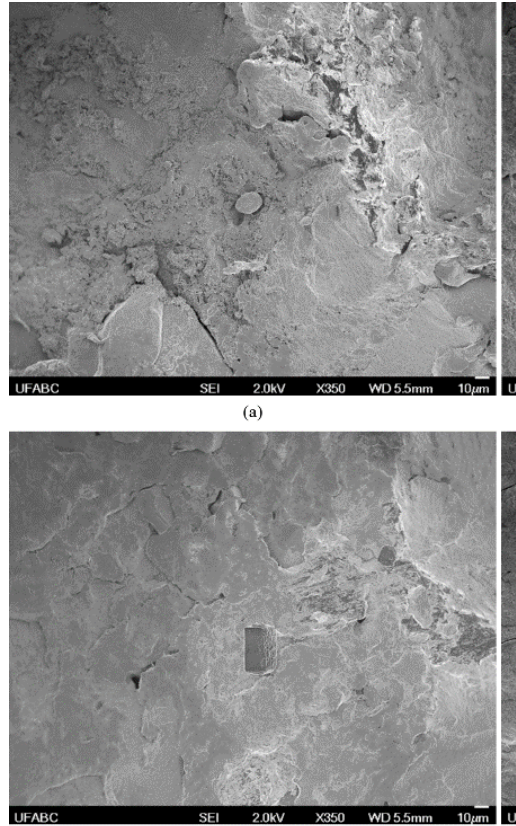

(d)

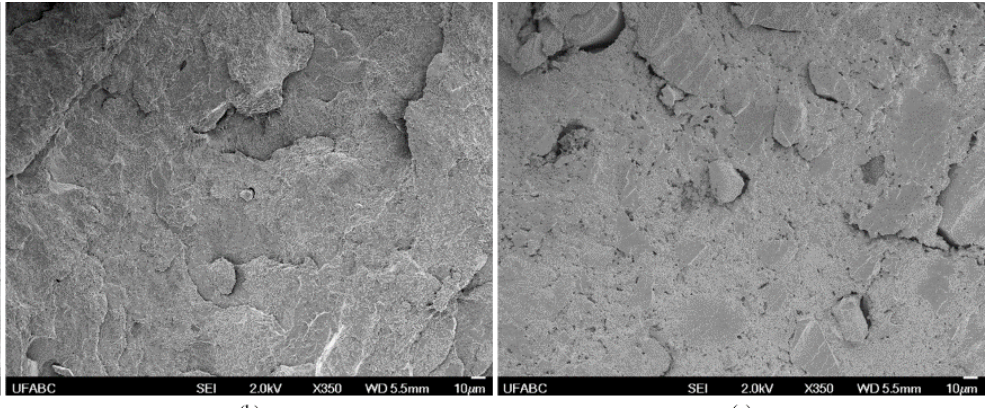

(b)

(c)

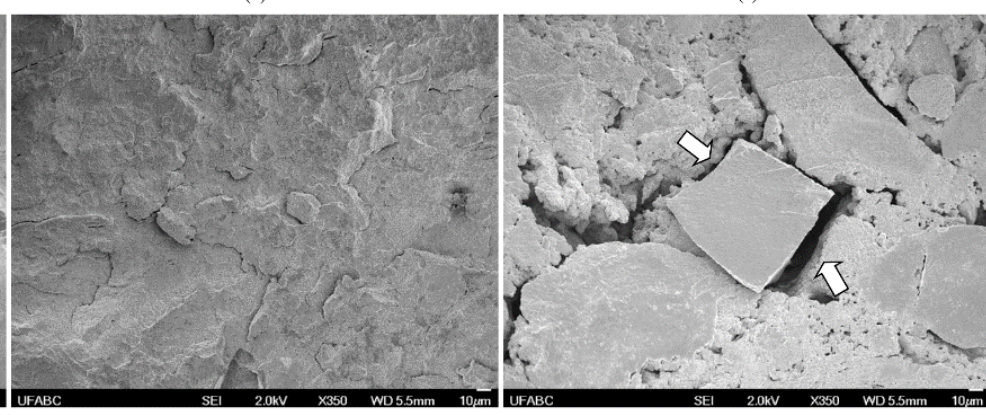

(1)

Figure 5. SEM micrographs of the blends: (a) 80GTR0/20HDPE, (b) 80GTR0+ad/20HDPE, (c) 80GTR3+ad/20HDPE, (d) 80GTR4+ad/20HDPE, (e) 80GTR2-2+ad/20HDPE, (f) 80GTR3-3+ad/20HDPE. 
Table 5. Values of melting temperature, enthalpy of melting $\left(\Delta \mathrm{H}_{\mathrm{m}}\right)$ and crystallization degree $\left(\chi_{\mathrm{c}}\right)$ of the HDPE phase of the blends.

\begin{tabular}{cccccccc}
\hline Sample & $\begin{array}{c}\mathbf{T}_{\mathbf{m}} \\
\left({ }^{\circ} \mathbf{C}\right)\end{array}$ & $\begin{array}{c}\Delta \mathbf{H}_{\mathrm{m}} \\
(\mathbf{J} / \mathbf{g})\end{array}$ & $\begin{array}{c}\chi_{\mathrm{C}} \\
(\mathbf{\%})\end{array}$ & Sample & $\begin{array}{c}\mathbf{T}_{\mathbf{m}} \\
\left({ }^{\circ} \mathbf{C}\right)\end{array}$ & $\begin{array}{c}\Delta \mathbf{H}_{\mathrm{m}} \\
(\mathbf{J} / \mathbf{g})\end{array}$ & $\begin{array}{c}\chi_{\mathbf{c}} \\
(\mathbf{\%})\end{array}$ \\
\hline HDPE & 141.74 & 183.72 & 62.70 & & & & \\
80GTR0/20HDPE & 134.86 & 52.84 & 90.17 & $80 \mathrm{GTR} 4+\mathrm{ad} / 20 \mathrm{HDPE}$ & 133.81 & 39.02 & 66.59 \\
80GTR0+ad/20HDPE & 132.12 & 33.57 & 57.29 & $80 \mathrm{GTR} 5+\mathrm{ad} / 20 \mathrm{HDPE}$ & 135.79 & 52.03 & 88.79 \\
80GTR1+ad/20HDPE & 133.93 & 41.38 & 70.61 & $80 \mathrm{GTR} 2-2+\mathrm{ad} / 20 \mathrm{HDPE}$ & 133.46 & 51.75 & 88.30 \\
80GTR2+ad/20HDPE & 133.53 & 40.43 & 68.99 & $80 \mathrm{GTR} 2-2-2+\mathrm{ad} / 20 \mathrm{HDPE}$ & 136.65 & 54.56 & 93.10 \\
80GTR3+ad/20HDPE & 133.14 & 51.29 & 87.52 & $80 \mathrm{GTR} 3-3+\mathrm{ad} / 20 \mathrm{HDPE}$ & 133.77 & 46.66 & 79.63 \\
\hline
\end{tabular}

Table 6. Mechanical properties of the blends.

\begin{tabular}{|c|c|c|c|c|}
\hline Blend & $\begin{array}{c}\text { Young's modulus } \\
\text { (MPa) }\end{array}$ & $\begin{array}{c}\text { Stress at break } \\
\text { (MPa) }\end{array}$ & $\begin{array}{c}\text { Tensile strength } \\
\text { (MPa) }\end{array}$ & $\begin{array}{c}\text { Elongation at break } \\
(\mathrm{mm} / \mathrm{mm})\end{array}$ \\
\hline 80GTR0/20HDPE & $36.02 \pm 7.97$ & $60.61 \pm 5.45$ & $2.72 \pm 0.24$ & $0.40 \pm 0.06$ \\
\hline 80GTR0+ad/20HDPE & $33.33 \pm 1.99$ & $92.93 \pm 7.30$ & $4.30 \pm 0.34$ & $0.59 \pm 0.10$ \\
\hline 80GTR1+ad/20HDPE & $27.98 \pm 0.67$ & $54.87 \pm 8.36$ & $3.01 \pm 0.46$ & $0.25 \pm 0.06$ \\
\hline 80GTR2+ad/20HDPE & $30.60 \pm 1.98$ & $80.59 \pm 6.56$ & $3.67 \pm 0.34$ & $0.53 \pm 0.10$ \\
\hline 80GTR3+ad/20HDPE & $33.94 \pm 3.95$ & $79.98 \pm 5.02$ & $3.73 \pm 0.19$ & $0.40 \pm 0.06$ \\
\hline 80GTR4+ad/20HDPE & $37.30 \pm 3.54$ & $54.48 \pm 8.35$ & $2.99 \pm 0.46$ & $0.15 \pm 0.05$ \\
\hline 80GTR5+ad/20HDPE & $39.49 \pm 1.33$ & $64.36 \pm 15.95$ & $3.53 \pm 0.87$ & $0.16 \pm 0.05$ \\
\hline 80GTR2-2+ad/20HDPE & $25.01 \pm 0.86$ & $79.25 \pm 2.91$ & $4.26 \pm 0.94$ & $0.47 \pm 0.06$ \\
\hline 80GTR2-2-2+ad/20HDPE & $48.70 \pm 2.81$ & $53.63 \pm 10.62$ & $2.94 \pm 0.58$ & $0.19 \pm 0.05$ \\
\hline 80GTR3-3+ad/20HDPE & $57.02 \pm 3.37$ & $40.67 \pm 4.70$ & $2.23 \pm 0.18$ & $0.09 \pm 0.01$ \\
\hline
\end{tabular}

strength of the blends did not vary significantly with the increase of the exposure time of the GTR to microwaves.

According to Prut et al. ${ }^{[36]}$, Young's modulus depends on the crystallinity development during the quenching. With the increase of the crystallinity, the matrix became tougher, which led to the increase of the Young's modulus. The increase of the crystallinity of the matrix could also generate less perfect crystals, which also may have resulted into an increase of the Young's modulus values.

Another observation is that, in general, the results obtained were not so good, especially the results of elongation at break, for blends which are supposed to be TPVs. According to Hong and Isayev ${ }^{[19]}$, adhesion between the GRT and polymer matrix is one of the major factors controlling the mechanical properties of such blends. Also, according to some authors ${ }^{[43,44]}$, deterioration on the elongation at break is due to the poor interfacial adhesion between the phases. According to the presented results, adhesion between the phases was not sufficient to promote good stress transference.

The blends containing GTR 0 and vulcanization additives presented higher mechanical properties in comparison to the same ones without additives. These results showed that the dynamic revulcanization improves the mechanical properties, as also observed by other authors ${ }^{[39,45-51]}$.

Luo and Isayev ${ }^{[46]}$ studied the properties of the blends polypropylene (PP)/GTR devulcanized by ultrasound using different curing systems and processing routes, and all the blends presented low elongation at break. Some other authors ${ }^{[19,52]}$ also achieved the same results. The reason for this behavior is the large size of rubber particles and the premature curing of this phase when the curatives are poorly distributed in the rubber ${ }^{[46]}$. Also, according to Antunes et al. ${ }^{[22]}$, when the dynamic vulcanization happens, the curatives are not well distributed by the batch mixer, resulting in different levels of cross-linkings. In the present work, this problem was avoided, since the vulcanization agents were previously added in the rubber phase and mixed by using a two roll mill. So, the reason for the poor mechanical properties is probably the lack of adhesion between the phases.

One of the qualifying standards for a blend to be deemed as a TPV is to present typical elastomeric elongation, which has also not been verified in the obtained results. However, these blends have high concentrations of GTR phase $(80 \%$ in mass), a recycled material, what may have deteriorated the mechanical properties. Grigoryeva et al. ${ }^{[53]}$ produced dynamically vulcanized blends using GTR, and in some of the production methods used by the authors, TPVs were also not obtained. According to the authors, in these cases there was not an effective interfacial stress transference between the phases, and not an entanglement of the GTR rubber chains into the surrounding matrix. These facts could also have happened in this work. Therefore, additional studies must be performed, taking into consideration the use of compatibilizer additives or a way to improve the interfacial characteristics of the blends like using nanofillers.

\section{Conclusions}

The dynamically revulcanized blends based on GTR devulcanized by microwaves (under different exposure times) and HDPE were analyzed by different techniques. According to the torque development during the mixing process, dynamic revulcanization was faster than the revulcanization of the neat rubber, due to the high shear rates generated during the processing. The oscillatory rheometry results showed that the lack of adhesion between the phases influenced the rheological properties of the blends, which resulted into poor mechanical properties, especially in the blends containing GTR exposed to microwaves for longer 
exposure times. The dynamic mechanical properties showed that there were differences in the $\mathrm{T}_{\mathrm{g}}$ values of the elastomeric phase, depending on the exposure time to microwaves. However, no conclusion about the morphology refinement of the blends can be made based on the SEM micrographs.

Summarizing, devulcanization process of GTR can change completely the final properties of the revulcanized blends 80GTR/20HDPE, since it changes the fluidity of rubber during processing. The process parameters like exposure time can be analyzed based on the final properties of these blends. Devulcanization by microwaves can be a strong alternative to solve the problem of disposal of waste rubber.

\section{Acknowledgements}

The authors would like to thank Braskem and Pirelli for the material donation, Departamento de Engenharia de Materiais - DEMa, Universidade Federal de São Carlos for the laboratory facilities, FAPESP (process number 2010/15799-6) and CNPq (process number 201891/2011-5) for the financial support.

\section{References}

1. Wu, B., \& Zhou, M. H. (2009). Recycling of waste tyre rubber into oil absorbent. Waste Management, 29(1), 355-359. http:// dx.doi.org/10.1016/j.wasman.2008.03.002. PMid:18455384.

2. Roche, N., Ichchou, M. N., Salvia, M., \& Chettah, A. (2011). Dynamic Damping Properties of Thermoplastic Elastomers Based on EVA and Recycled Ground Tire Rubber. Journal of Elastomers and Plastics, 43(4), 317-340. http://dx.doi. org/10.1177/0095244311398631.

3. Scuracchio, C. H., Waki, D. A., \& Bretas, R. E. S. (2006). Caracterização Térmica e Reológica de Borracha de Pneu Desvulcanizada por Microondas. Polímeros: Ciência e Tecnologia, 16(1), 46-52.

4. Scuracchio, C. H., Waki, D. A., \& da Silva, M. (2007). Thermal analysis of ground tire rubber devulcanized by microwaves. Journal of Thermal Analysis and Calorimetry, 87(3), 893-897. http://dx.doi.org/10.1007/s10973-005-7419-8.

5. Novotny, D. S., Marsh, R. I., Masters, F. C., \& Tally, D. N. (1978). US Patent 4.104.205. United States: Goodyear Tire \& Rubber Company.

6. Leonelli, C., \& Mason, T. J. (2010). Microwave and ultrasonic processing: Now a realistic option for industry. Chemical Engineering and Processing, 49(9), 885-900. http://dx.doi. org/10.1016/j.cep.2010.05.006.

7. Thostenson, E. T., \& Chou, T. W. (1999). Microwave processing: fundamentals and applications. Composites: Part A, Applied Science and Manufacturing, 30(9), 1055-1071. http://dx.doi. org/10.1016/S1359-835X(99)00020-2.

8. Amari, T., Themelis, N. J., \& Wernick, I. K. (1999). Resource recovery from used rubber tires. Resources Policy, 25(3), 179188. http://dx.doi.org/10.1016/S0301-4207(99)00025-2.

9. Sun, X., Isayev, A. I., Joshi, T. R., \& von Meerwall, E. (2007). Molecular mobility of unfilled and carbon-black-filled isoprene rubber: Proton NMR transverse relaxation and diffusion. Rubber Chemistry and Technology, 80(5), 854-872. http://dx.doi. org/10.5254/1.3539421.

10. Pistor, V., Ornaghi, F. G., Fiorio, R., Zattera, A. J., Oliveira, P. J., \& Scuracchio, C. H. (2010). Devulcanization of EthylenePropylene-Diene Polymer Residues (EPDM-r) by Microwaves. Polimeros: Ciência e Tecnologia, 20(3), 165-169.

11. Bani, A., Polacco, G., \& Gallone, G. (2011). Microwave-Induced Devulcanization for Poly(ethylene-propylene-diene) Recycling.
Journal of Applied Polymer Science, 120(5), 2904-2911. http:// dx.doi.org/10.1002/app.33359.

12. van Duin, M., \& Machado, A. V. (2005). EPDM-based thermoplastic vulcanisates: Crosslinking chemistry and dynamic vulcanisation along the extruder axis. Polymer Degradation \& Stability, 90(2), 340-345. http://dx.doi.org/10.1016/j.polymdegradstab.2005.04.050.

13. Lee, S. H., Balasubramanian, M., \& Kim, J. K. (2007). Dynamic reaction inside co-rotating twin screw extruder. I. Truck tire model material/polypropylene blends. Journal of Applied Polymer Science, 106(5), 3193-3208. http://dx.doi.org/10.1002/ app.26489.

14. Isayev, A. I., Yushanov, S. P., Kim, S. H., \& Levin, V. Y. (1996). Ultrasonic devulcanization of waste rubbers: Experimentation and modeling. Rheologica Acta, 35(6), 616-630. http://dx.doi. org/10.1007/BF00396511.

15. Isayev, A. I., Chen, J., \& Tukachinsky, A. (1995). Novel ultrasonic technology for devulcanization of waste rubbers. Rubber Chemistry and Technology, 68(2), 267-280. http:// dx.doi.org/10.5254/1.3538741.

16. Oh, J. S., Ghose, S., \& Isayev, A. I. (2003). Effects of ultrasonic treatment on unfilled butadiene rubber. Journal of Polymer Science: Part B, Polymer Physics, 41(22), 2959-2968. http:// dx.doi.org/10.1002/polb.10606.

17. Sun, X. M., \& Isayev, A. I. (2008). Continuous ultrasonic devulcanization comparison of carbon black filled synthetic isoprene and natural rubbers. Rubber Chemistry and Technology, 81(1), 19-46. http://dx.doi.org/10.5254/1.3548195.

18. Sousa, F. D. B., \& Scuracchio, C. H. (2012). Vulcanization behavior of NBR with organically modified clay. Journal of Elastomers and Plastics, 44(3), 263-272. http://dx.doi. org $/ 10.1177 / 0095244311424722$.

19. Hong, C. K., \& Isayev, A. I. (2001). Plastic/rubber blends of ultrasonically devulcanized GRT with HDPE. Journal of Elastomers and Plastics, 33(1), 47-71. http://dx.doi.org/10.1106/5AMQXEAY-A05B-P1FY.

20. Hirayama, D., \& Saron, C. (2012). Chemical Modifications in Styrene-Butadiene Rubber after Microwave Devulcanization. Industrial \& Engineering Chemistry Research, 51(10), 39753980. http://dx.doi.org/10.1021/ie202077g.

21. Shahbikian, S., Carreau, P. J., Heuzey, M. C., Ellul, M. D., Cheng, J., Shirodkar, P., \& Nadella, H. P. (2012). Morphology development of EPDM/PP uncross-linked/dynamically crosslinked blends. Polymer Engineering and Science, 52(2), 309-322. http://dx.doi.org/10.1002/pen.22084.

22. Antunes, C. F., Machado, A. V., \& van Duin, M. (2011). Morphology development and phase inversion during dynamic vulcanisation of EPDM/PP blends. European Polymer Journal, 47(7), 1447 1459. http://dx.doi.org/10.1016/j.eurpolymj.2011.04.005.

23. Antunes, C. F., van Duin, M., \& Machado, A. V. (2011). Morphology and phase inversion of EPDM/PP blends - Effect of viscosity and elasticity. Polymer Testing, 30(8), 907-915. http://dx.doi.org/10.1016/j.polymertesting.2011.08.013.

24. Antunes, C. F., van Duin, M., \& Machado, A. V. (2012). Effect of crosslinking on morphology and phase inversion of EPDM/ PP blends. Materials Chemistry and Physics, 133(1), 410-418. http://dx.doi.org/10.1016/j.matchemphys.2012.01.053.

25. Mani, S., Cassagnau, P., Bousmina, M., \& Chaumont, P. (2011). Morphology Development in Novel Composition of Thermoplastic Vulcanizates Based on PA12/PDMS Reactive Blends. Macromolecular Materials and Engineering, 296(10), 909-920. http://dx.doi.org/10.1002/mame.201000406.

26. Asaletha, R., Kumaran, M. G., \& Thomas, S. (1999). Thermoplastic elastomers from blends of polystyrene and natural rubber: morphology and mechanical properties. European Polymer Journal, 35(2), 253-271. http://dx.doi.org/10.1016/S00143057(98)00115-3.

27. Babu, R. R., Singha, N. K., \& Naskar, K. (2009). Dynamically Vulcanized Blends of Polypropylene and Ethylene Octene 
Copolymer: Influence of Various Coagents on Mechanical and Morphological Characteristics. Journal of Applied Polymer Science, 113(5), 3207-3221. http://dx.doi.org/10.1002/app.30000.

28. Babu, R. R., Singha, N. K., \& Naskar, K. (2010). Interrelationships of morphology, thermal and mechanical properties in uncrosslinked and dynamically crosslinked PP/EOC and PP/EPDM blends. Express Polymer Letters, 4(4), 197-209. http://dx.doi.org/10.3144/ expresspolymlett.2010.26.

29. Babu, R. R., Singha, N. K., \& Naskar, K. (2010). Effects of mixing sequence on peroxide cured polypropylene (PP)/ethylene octene copolymer (EOC) thermoplastic vulcanizates (TPVs). Part. I. Morphological, mechanical and thermal properties. Journal of Polymer Research, 17(5), 657-671. http://dx.doi. org/10.1007/s10965-009-9354-z.

30. Mirzadeh, A., Lafleur, P. G., Kamal, M. R., \& Dubois, C. (2012). The effects of nanoclay dispersion levels and processing parameters on the dynamic vulcanization of TPV nanocomposites based on PP/EPDM prepared by reactive extrusion. Polymer Engineering and Science, 52(5), 1099-1110. http://dx.doi. org/10.1002/pen.22178.

31. Babu, R. R., Singha, N. K., \& Naskar, K. (2011). Phase morphology and melt rheological behavior of uncrosslinked and dynamically crosslinked polyolefin blends: role of macromolecular structure. Polymer Bulletin, 66(1), 95-118. http://dx.doi.org/10.1007/ s00289-010-0328-4.

32. Cao, L. M., Cao, X. D., Jiang, X. J., Xu, C. H., \& Chen, Y. K. (2013). In situ reactive compatibilization and reinforcement of peroxide dynamically vulcanized polypropylene/ethylenepropylene-diene monomer tpv by zinc dimethacrylate. Polymer Composites, 34(8), 1357-1366. http://dx.doi.org/10.1002/ pc. 22550 .

33. Cui, L. M., Zhou, Z., Zhang, Y., Zhang, Y. X., Zhang, X. F., \& Zhou, W. (2007). Rheological behavior of polypropylene/ novolac blends. Journal of Applied Polymer Science, 106(2), 811-816. http://dx.doi.org/10.1002/app.26515.

34. Rajeshbabu, R., Gohs, U., Naskar, K., Thakur, V., Wagenknecht, U., \& Heinrich, G. (2011). Preparation of polypropylene (PP)/ ethylene octene copolymer (EOC) thermoplastic vulcanizates (TPVs) by high energy electron reactive processing. Radiation Physics and Chemistry, 80(12), 1398-1405. http://dx.doi. org/10.1016/j.radphyschem.2011.07.001.

35. Tang, Y. C., Lu, K., Cao, X. J., \& Li, Y. J. (2013). Nanostructured Thermoplastic Vulcanizates by Selectively Cross-Linking a Thermoplastic Blend with Similar Chemical Structures. Industrial \& Engineering Chemistry Research, 52(35), 12613-12621. http://dx.doi.org/10.1021/ie401853k.

36. Prut, E. V., Erina, N. A., Karger-Kocsis, J., \& Medintseva, T. I. (2008). Effects of blend composition and dynamic vulcanization on the morphology and dynamic viscoelastic properties of PP/ EPDM blends. Journal of Applied Polymer Science, 109(2), 1212-1220. http://dx.doi.org/10.1002/app.28158.

37. Babu, R. R., Singha, N. K., \& Naskar, K. (2009). Dynamically Vulcanized Blends of Polypropylene and Ethylene-Octene Copolymer: Comparison of Different Peroxides on Mechanical, Thermal, and Morphological Characteristics. Journal of Applied Polymer Science, 113(3), 1836-1852. http://dx.doi.org/10.1002/ app.30076.

38. Babu, R. R., Singha, N. K., \& Naskar, K. (2011). Effects of mixing sequence on peroxide cured polypropylene (PP)/ethylene octene copolymer (EOC) thermoplastic vulcanizates (TPVs). Part. II. Viscoelastic characteristics. Journal of Polymer Research, 18(1), 31-39. http://dx.doi.org/10.1007/s10965-010-9388-2.

39. George, J., Varughese, K. T., \& Thomas, S. (2000). Dynamically vulcanised thermoplastic elastomer blends of polyethylene and nitrile rubber. Polymer, 41(4), 1507-1517. http://dx.doi. org/10.1016/S0032-3861(99)00302-X.

40. Machado, M. L. C., Pereira, N. C., de Miranda, L. E., Terence, M. C., \& Pradella, J. G. C. (2010). Study of Mechanical and
Thermal Properties of the Polymer Poly-3-Hydroxybutyrate (PHB) and PHB/Wood Flour Composites. Polímeros: Ciencia e Tecnologia, 20(1), 65-71.

41. Huang, X. Y., Ke, Q. Q., Kim, C. N., Zhong, H. F., Wei, P., Wang, G. L., Liu, F., \& Jiang, P. K. (2007). Nonisothermal crystallization behavior and nucleation of LDPE/Al nano- and microcomposites. Polymer Engineering and Science, 47(7), 1052-1061. http://dx.doi.org/10.1002/pen.20784.

42. Utracki, L. A. (2002). Polymer blends handbook. Netherlands: Kluwer Academic Publishers.

43. Chen, J., Chen, J. W., Chen, H. M., Yang, J. H., Chen, C., \& Wang, Y. (2013). Effect of compatibilizer and clay on morphology and fracture resistance of immiscible high density polyethylene/ polyamide 6 blend. Composites: Part B, Engineering, 54, 422430. http://dx.doi.org/10.1016/j.compositesb.2013.06.014.

44. Kahar, A. W. M., Ismail, H., \& Othman, N. (2013). Properties of HVA-2 vulcanized high density polyethylene/natural rubber/ thermoplastic tapioca starch blends. Journal of Applied Polymer Science, 128(4), 2479-2488. http://dx.doi.org/10.1002/app.38471.

45. Anandhan, S., \& Bhowmick, A. K. (2013). Thermoplastic vulcanizates from post consumer computer plastics/nitrile rubber blends by dynamic vulcanization. Journal of Material Cycles and Waste Management, 15(3), 300-309. http://dx.doi. org/10.1007/s10163-012-0112-7.

46. Luo, T., \& Isayev, A. I. (1998). Rubber/plastic blends based on devulcanized ground tire rubber. Journal of Elastomers and Plastics, 30(2), 133-160.

47. Corley, B. E., \& Radusch, H. J. (1998). Intensification of interfacial interaction in dynamic vulcanization. Journal of Macromolecular Science-Physics, 37(2), 265-273. http://dx.doi. org/10.1080/00222349808220471.

48. Babu, R. R., Singha, N. K., \& Naskar, K. (2008). Studies on the influence of structurally different peroxides in polypropylene/ ethylene alpha olefin thermoplastic vulcanizates (TPVs). Express Polymer Letters, 2(3), 226-236. http://dx.doi.org/10.3144/ expresspolymlett.2008.27.

49. Supri, I. H., \& Ismail, H. (2006). Effects of dynamic vulcanization and glycidyl methacrylate on properties of recycled poly(vinyl chloride)/acrylonitrile butadiene rubber blends. Polymer Testing, 25(3), 318-326. http://dx.doi.org/10.1016/j. polymertesting.2006.01.001.

50. Wahab, M. K. A., Ismail, H., \& Othman, N. (2012). Effects of dynamic vulcanization on the physical, mechanical, and morphological properties of high-density polyethylene/(natural rubber)/(thermoplastic tapioca starch) blends. Journal of Vinyl \& Additive Technology, 18(3), 192-197. http://dx.doi.org/10.1002/ vnl.20311.

51. Gheno, S. M., Passador, F. R., \& Pessan, L. A. (2010). Investigation of the Phase Morphology of Dynamically Vulcanized PVC/NBR Blends Using Atomic Force Microscopy. Journal of Applied Polymer Science, 117(6), 3211-3219.

52. Jose, S., Nair, S. V., Thomas, S., \& Karger-Kocsis, J. (2006). Effect of reactive compatibilisation on the phase morphology and tensile properties of PA12/PP blends. Journal of Applied Polymer Science, 99(5), 2640-2660. http://dx.doi.org/10.1002/ app. 22806 .

53. Grigoryeva, O. P., Fainleib, A. M., Tolstov, A. L., Starostenko, O. M., Lievana, E., \& Karger-Kocsis, J. (2005). Thermoplastic Elastomers based on recycled high-density polyethylene, ethylene-propylene-diene monomer rubber, and ground tire rubber. Journal of Applied Polymer Science, 95(3), 659-671. http://dx.doi.org/10.1002/app.21177.

Received: Apr. 14, 2014

Revised: Oct. 07, 2014

Accepted: Nov. 11, 2014 